\title{
MEMBANGUN IMAJINASI WISATAWAN MELALUI PENGALAMAN PERJALANAN DI KAWASAN WISATA WARISAN BUDAYA
}

\author{
Rista $^{1}$, Nikasisus Jonet Sinangjoyo ${ }^{2}$, Fian Damasdino ${ }^{3}$ \\ ${ }^{I}$ Sekolah Tinggi Pariwisata AMPTA Yogyakarta, Indonesia,Email: ristayasin19@gmail.com
}

\begin{abstract}
=
ABSTRAK

Histori Artikel

Submitted:

20 September 2019

Reviewed:

1 Oktober 2019

Accepted:

1 November 2019

Published:

15 November 2019

Penelitian ini bertujuan untuk membangun imajinasi wisatawan melalui pengalaman perjalanan di kawasan wisata warisan budaya. Penulis menganalisis imajinasi yang diperoleh wisatawan dengan menggunakan tujuh faktor : fasilitas penginapan dan makan, aksesibilitas internal, atraksi terdekat, aksesibilitas eksternal, sistem keselamatan dan darurat, atraksi di tempat dan penyediaan layanan informasi. Pengumpulan data dengan cara observasi, wawancara, FGD, dokumentasi, dan studi pustaka melalui analisis data kualitatif deskriptif. Hasil penelitian menunjukkan bahwa mitos kolam pemandian paling dominan dalam membangun imajinasi wisatawan dan menjadi alasan utama wisatawan berkunjung ke Tamansari. Umumnya wisatawan bisa membayangkan mitos yang disampaikan oleh pemandu wisata dan cenderung menggambarkan Tamansari sebagai tempat yang indah di masa lalu. Pengalaman perjalanan yang didapatkan wisatawan selama berwisata di Tamansari yaitu mitos, sejarah, dan aktivitas di lokasi. Faktor yang paling dominan membangun imajinasi wisatawan melalui penglaman perjalanan adalah (1) Aksesibilitas eksternal (2) faktor atraksi di tempat yiatu mitos (3) atraksi terdekat.
\end{abstract}

Kata Kunci: wisata heritage, wisatawan, pengalaman, imajinasi

\section{BUILDING TOURISM IMAGINATION THROUGH TRAVEL EXPERIENCE IN CULTURAL HERITAGE TOURISM AREA}

\begin{abstract}
This research aims to build the imagination of tourists through travel experiences in the cultural heritage tourism area. The author analyzes the imagination gained by tourists using seven factors: lodging and dining facilities, internal accessibility, nearby attractions, external accessibility, safety and emergency systems, on-site attractions and the provision of information services. Data collection by observation, interview, FGD, documentation, and literature study through descriptive qualitative data analysis. The results showed that the myth of the bathing pool was the most dominant in building the imagination of tourists and became the main reason for tourists visiting Tamansari. Generally tourists can imagine the myths conveyed by tour guides and tend to portray Tamansari as a beautiful place in the past. Travel experiences gained by tourists during a tour in Tamansari are myths, history, and activities at the location. The most dominant factors that build the imagination of tourists through travel experience are (1) external accessibility (2) attraction factors in places where myths (3) nearby attractions
\end{abstract}

Keywords: heritage tourism, tourists, experience, imagination 


\section{PENDAHULUAN}

Sektor pariwisata merupakan industri perdagangan jasa terbesar di dunia yang saat ini mampu menyerap tenaga kerja. Salah satu ragam jenis wisata yang berkembang di Indonesia adalah pariwisata warisan budaya. Warisan/cagar budaya adalah warisan budaya bersifat kebendaan berupa benda cagar budaya, bangunan cagar budaya, struktur cagar budaya, situs cagar budaya, dan kawasan cagar budaya di darat dan/atau di air yang perlu dilestarikan keberadaannya karena memiliki nilai penting bagi sejarah, ilmu pengetahuan, pendidikan, agama, dan/atau kebudayaan melalui proses penetapan (Undang-Undang Nomor 11 Tahun 2010).

Yogyakarta merupakan kota yang dikenal sebagai daerah tujuan wisata yang sangat populer di Indonesia. Yogyakarta juga terkenal sebagai kota sejarah karena mayoritas terdapat peninggalan bersejarah berupa candi berusia ribuan tahun dan bangunan peninggalan kerajaan jaman dahulu yang masih dapat dinikmati hingga saat ini. Setiap peninggalan bersejarah tersebut memiliki nilai khas dan keunikan tersendiri. Salah satu hal yang menjadi daya tarik dari sebuah peninggalan di Yogyakarta adalah cerita rakyat (folklore).

Salah satu destinasi wisata yang terkenal dengan cerita rakyatnya adalah Tamansari. Tamansari (water castle) merupakan sebuah kawasan warisan budaya Keraton Kesultanan Yogyakarta yang masih berdiri kokoh. Tamansari memiliki keindahan pada arsitektur bangunan yang kuno dan pemandangan yang indah.

Selain keindahan yang dimiliki bangunan Tamansari juga penuh dengan cerita mitos. Beberapa cerita Tamansari yang terkenal adalah cerita mengenai kolam pemandian raja dan selir-selirnya. Pada zamannya, selain Sultan, hanya para perempuan yang diizinkan untuk masuk ke kompleks ini. Ini dikarenakan semua perempuan (permaisuri, istri/selir dan para putri sultan) yang masuk ke dalam Tamansari hanya memakai baju kain penutup dada (kain kemben), sehingga selain perempuan di larang keras oleh sultan untuk masuk ke Tamansari.

Imajinasi adalah daya pikir untuk membayangkan atau menciptakan "gambar" yang mencakup kondisi, karangan, lukisan, atau lainnya, dari sebuah kejadian berdasarkan kenyataan atau pengalaman seseorang. Melalui proses imajinasi ini, individu secara langsung terhubung dengan alam atau benda-benda alami. Dengan demikian, ada proses siklus antara imajinasi keindahan estetika alami dan kepuasan keindahan yang mendorong imajinasi lebih lanjut. Berdasarkan penelitian yang dilakukan oleh Xiaobo $\mathrm{Su}$ (2010) menunjukan bagaimana wisatawan membayangkan suatu tempat wisata sebagai tujuan sejarah.

Imajinasi wisatawan memainkan peran penting dalam menginstruksikan konsumsi mereka. Konsumsi pariwisata termasuk menatap, menyentuh dan mendengarkan. Melalui menatap, wisatawan menangkap keindahan bangunan melalui sentuhan, mereka membangun ekonomi dan koneksi sosial dengan lingkungan sekitar, melalui mendengarkan, mereka mengembangkan lebih banyak keterlibatan dengan budaya lokal untuk memverifikasi bahwa suatu tempat tersebut memang unik. Ketika mengunjungi wisata yang merupakan peninggalan masa lalu, wisatawaan seakanakan sedang diajak berwisata ke masa lalu. Imajinasi yang sudah didapatkan selanjutnya akan memberikan pengalaman perjalanan.

Pengalaman perjalanan adalah
pengetahuan dan kemampuan tentang perjalanan yang pernah dialami individu dimasa lalu secara personal, terbentuk oleh keinginan untuk mengalami perubahan diri dan bergantung oleh karakteristik kebutuhan individu. Pengalaman wisatawan terbentuk karena peristiwa yang dialaminya, jika dihubungkan dengan pengalaman perjalanan di Tamansari wisatawan akan mendapatkan pengalaman perjalanan jika wisatawan mengikuti secara keseluruhan alur yang ada di Tamansari. 
Wisatawan yang menggunakan jasa pemandu akan mendapatkan pengalaman perjalanan. Pada penelitian yang dilakukan oleh Cheng Fei, Lee (2015) menafsirkan pengalaman perjalanan melalui tujuh faktor, yaitu : Fasilitas penginapan dan makan, aksesibilitas internal, atraksi terdekat,aksesibilitas eksternal, penyediaan sistem keselamatan dan darurat, atraksi di tempat, penyediaan layanan informasi.

\section{LITERATUR REVIEW}

\section{Pariwisata Warisan Budaya (Heritage Tourism)}

Pariwisata Warisan Budaya atau heritage tourism biasanya disebut juga dengan pariwisata pusaka budaya (cultural and heritage tourism atau cultural heritage tourism) atau lebih spesifik disebut dengan pariwisata pusaka budaya dan alam. Pusaka adalah segala sesuatu (baik yang bersifat materi maupun non materi) yang diwariskan dari satu generasi ke generasi (Rusli Cahyadi, 2009). Pariwisata warisan budaya juga dimaknai dengan pertemuan pribadi dengan tradisi, sejarah, dan budaya. Pariwisata warisan budaya didasarkan pada konsep bahwa masing-masing komunitas memiliki sebuah cerita untuk diceritakan (Bruce, G. 2010).

Sedangkan Pitana dan Diarta (2009) berpendapat sumber daya budaya yang bisa dikembangkan menjadi daya tarik wisata diantaranya: (1) bangunan bersejarah, situs, monumen, museum, galeri seni, situs budaya, (2) Seni dan patung kontemporer, arsitektur, tekstil, pusat kerajinan tangan dan seni, pusat desain, studio artis, industri film dan penerbit, (3) Seni pertunjukan, drama, sendratari, lagu daerah teater jalanan, eksibisi foto, festival, (4) Peninggalan keagamaan seperti pura, candi, masjid, situs, (5) Kegiatan dan cara hidup masyarakat lokal, sistem pendidikan, sanggar, teknologi tradisional, cara kerja, dan sistem kehidupan setempat (6) Perjalanan (trekking) ke tempat bersejarah menggunakan alat transportasi unik, (7) Mencoba kuliner atau masakan setempat, persiapan, cara membuat, menyajikan, dan menyantapnya.

\section{Pengalaman Perjalanan (Tour Experience)}

Pengalaman (experience) berasal dari dua kata yang digabungkan di dalam bahasa latin yaitu experientia yang berarti pengetahuan yang diperoleh melalui pengulangan jejak (repeated trails) dan experiri yang berarti untuk mencoba, menguji (Rijal dan Ghimire, 2016).

Pengalaman wisatawan didapatkan dari apa yang dirasakan wisatawan terhadap suatu produk wisata yang diterimannya saat berwisata. (Pitana dan Diarta, 2009) berpendapat bahwa wisatawan melakukan kegiatan wisata dalam rangka mencari perjalanan yang mengesankan dari destinasi pariwisata yang dikunjungi, berarti yang dibutuhkan dari pencarian perjalanan adalah pengalaman yang mengesankan.

Pengalaman wisata yaitu semacam akumulasi fenomena psikologis, seperti yang terlihat dari perspektif psikologi, yang meliputi harapan sebelum perjalanan, persepsi selama perjalanan, dan kenangan setelah perjalanan (Sheng dan Chen, 2013 : 93). Pemahaman pengalaman dalam pariwisata mengarah pada subjek individu/wisatawan.

Walter et al (2010) mengartikan penglaman konsumen/customer experience sebagai pengalaman yang di dapatkan langsung maupun tidak langsung mengenai proses pelayanan, perusahaan, fasilitasfasilitas dan bagaimana cara seorang konsumen berinteraksi dengan perusahaan dan dengan konsumen lainnya. Hal ini pada gilirannya akan membuat respon kognitif, emosi dan perilaku konsumen yang meninggalkan kenangan konsumen tentang pengalaman saat dan setelah mengunjungi destinasi tersebut. Pengalaman wisatawan terjadi berdasarkan proses kegiatan yang dialaminya sendiri/individu.

Yuko dan Damayanti (2016) menunjukan bahwa faktor - faktor yang menjadi pembentuk pengalaman berwisata 
dan faktor dominan yang membentuk tourism experience adalah faktor conditional experience. Faktor conditional experience (Keindahan, Kepuasan, Cuaca, Rileks, Kesenangan, Nyaman, Event, Memorability, Pengetahuan).

Sedangkan pada penelitian yang dilakukan oleh Cheng Fei, Lee (2015) menafsirkan pengalaman wisatawan melalui tujuh faktor, yaitu : Fasilitas penginapan dan makan, aksesibilitas internal, atraksi terdekat, aksesibilitas eksternal, penyediaan sistem keselamatan dan darurat, atraksi di tempat, penyediaan layanan informasi.

\section{Imajinasi Wisatawan Imagination)}

(Tourist

Istilah imajinasi berasal sebagai konsep teori-teori sosial yang berbasis di Prancis yaitu psikoanalisis, filsafat dan teori sosial antropologi, sebagian besar. Dalam hubungan imajinasi dan pariwisata, konsep ini menawarkan diskusi terkait ideologi, wacana, pandangan dunia, narasi, mitos, representasi, gambar, dan sebagainya (Leite, 2014). Dalam hal mengidentifikasi imajiner pariwisata dilakukan dengan cara menempati peran instrumental seolah-olah nilai analitiknya tergantung pada bagaimana mereka dapat melayani fungsi-fungsi tertentu dalam kehidupan orang-orang (Sneath et al, 2009).

Pentingnya imajinasi pariwisata terletak pada pemahaman bahwa wisatawan menghasilkan rasa realitas dan dengan demikian dipahami sebagai mental, individu dan proses sosial yang menghasilkan kenyataan itu secara bersamaan memproduksinya (Salazar, 2010). Selain itu, penekanan pada kekuatan imajinasi pariwisata mengasumsikan bahwa semua wisatawan terlibat dan menindakinya. Selanjutnya mempertimbangkan bagaimana wisatawan mengalaminya, dan mengeksplorasi peran yang terbatas sebagai imajiner.

Penelitian yang dilakukan oleh Rafael Pires Basariez dan Hadyn Ingram (2013) menyatakan bahwa imajinasi dan pariwisata memiliki kesamaan sifat dan merupakan fenomena yang diinginkan, inspirasional dan kuat, yang dapat menciptakan gambar nonverbal. Imajinasi adalah sumber kepuasan intelektual bagi wisatawan yang tidak hanya menginginkan liburan tetapi juga menghargai stimulasi intelektual yang dapat mereka peroleh dari pengalaman itu.

Ketika seseorang membayangkan mengunjungi tempat yang indah, secara otomatis memperkuat asumsi bahwa tempat saat ini seseorang tinggal tidak cukup indah dantidak bisa membangkitkan sensasi estetika yang serupa. Asumsi ini mengubah seseorang menjadi wisatawan ketika bepergian ke tempat-tempat baru menawarkan kesempatan untuk mengakses manifestasi materi imajinasi. Schroeder memberikan contoh imajinasi semacam ini ketika ia menyebutkan, "Mungkin taman liar sangat berarti bagi saya karena itu adalah batu loncatan saya menjadi sedikit masa lalu, dengan flora hutan dari masa kecil saya yang berlimpah" (Schroeder, 2009). 


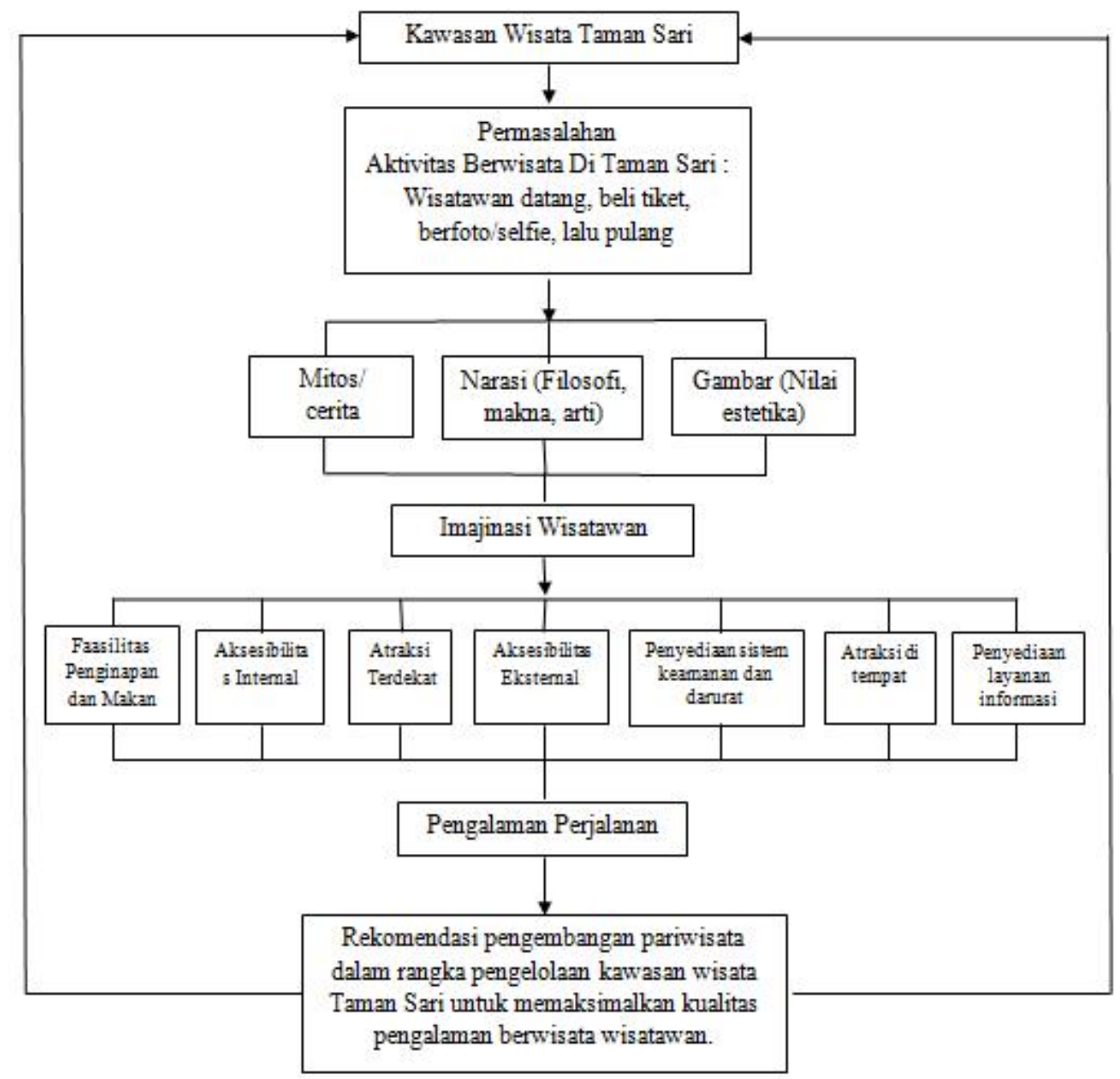

Gambar 1. Kerangka dasar penelitian Sumber: analisa penulis, 2019

\section{METODE PENELITIAN}

Penelitian ini meerupakan jenis penelitian berbasis data kualitatif. Lokasi penelitian dilakukan di kawasan wisata Situs Tamansari, Yogyakarta. Waktu penelitian selama 5 bulan. Pengumpulan data melalui pengamatan langsung (observasi), wawancara mendalam (indepht interview), dan Focus Group Discussion (FGD). Teknik memilih sampel penelitian dilakukan secara snowball sampling technique.

\section{HASIL DAN PEMBAHASAN}

\section{Gambaran Umum Lokasi Penelitian}

Tamansari merupakan salah satu bangunan bersejarah Keraton Yogyakarta yang memiliki arti "Taman yang indah". Didirikan oleh Sultan Hamengku Buwana I pada tahun Ehe 1684 Jw (1758 M), Pembangunan Tamansari ditandai dengan sengkalan memet atau prasasti catur nogo roso tunggal. Catur Nogo roso tunggal merupakan naga yang terdapat di depanTamansari yang melambangkan tahun jawa yaitu Catur=4, Naga=8, Rasa=6, Tunggal=1. (kratonjogja.id, 2019). 


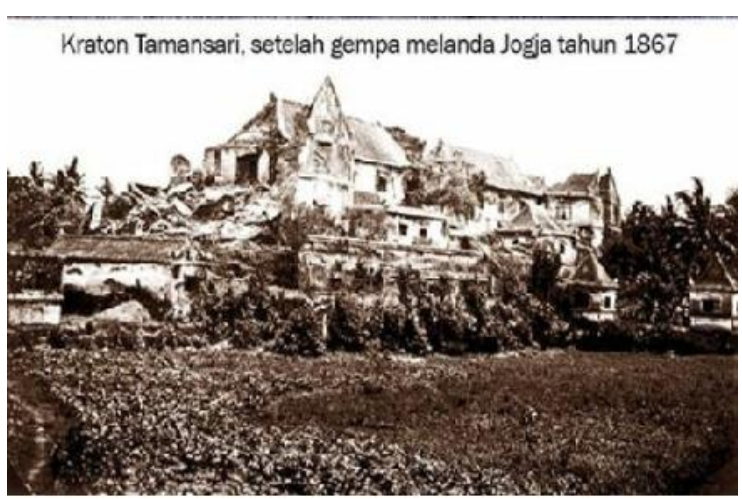

Gambar 2. Bentuk asli bangunan Tamansari Sumber : Instagram @jogjajamanold, 2019

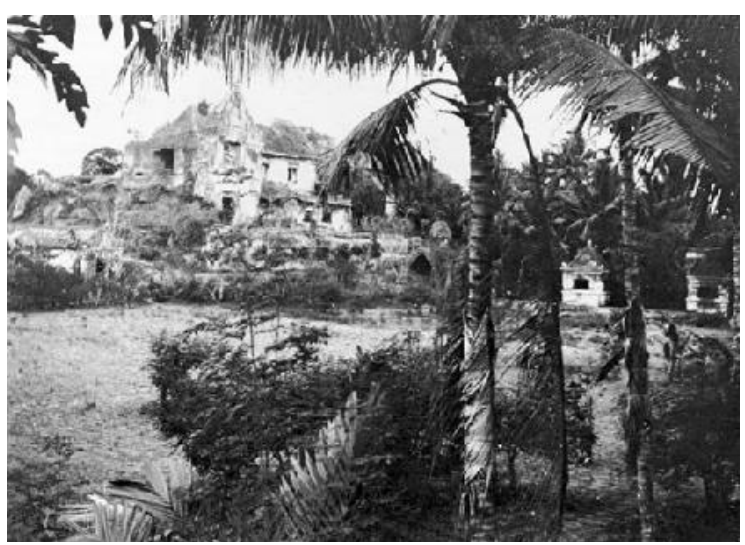

Gambar 3. Reruntuhan Tamansari, 1915

Sumber : Instagram @jogjajamanold, 2019

Tamansari menjadi tempat rekreasi dan kolam pemandian atau disebut pesanggrahan bagi Sultan Yogyakarta dan keluarganya. Tamansari dibangun sebagai lambang kejayaan Raja Mataram dan sering disebut sebagai Istana Air (water castle) yang memiliki nilai arsitektur pada lekukan bangunan dan air yang terisi dikolam yang hanya boleh dimasuki oleh keluarga inti Sultan. Istana air yang dikelilingi segaran atau danau buatan dengan wewangian dari bunga-bunga yang sengaja ditanam di pulau buatan disekitarnya. Lokasi Tamansari terletak 500 meter arah barat daya Keraton (Brosur Tamansari, 2019)

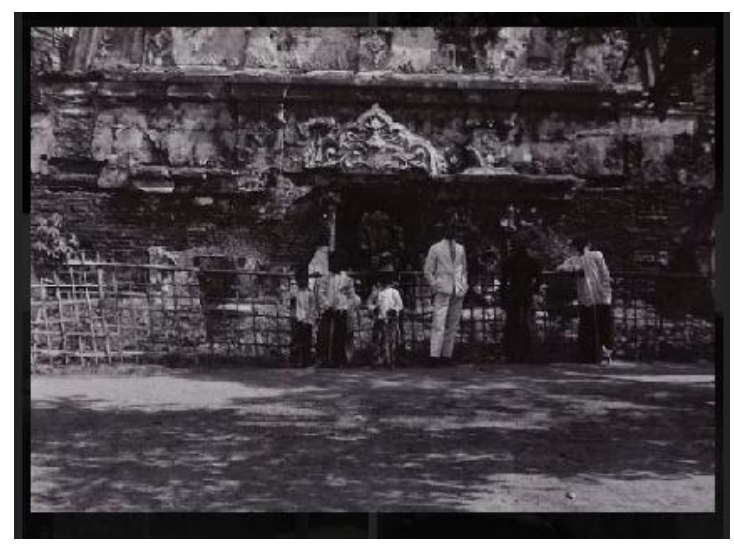

Gambar 4. Gapura Hageng Tamansari Sumber : Instagram @jogjajamanold, 2019

Tamansari efektif digunakan sekitar tahun 1765 - 1812 karena setelahnya terjadi beberapa peristiwa yang menghancurkan Situs Tamansari. Diantaranya adalah Peristiwa Geger Spehi dan Gempa bumi. Geger Sepehi merupakan peristiwa penyerbuan Kraton Yogyakarta yang dilakukan oleh pasukan Inggris pada tanggal 19-20 Juni 1812. Nama spehi berasal dari pasukan Sepoy yang dipekerjakan oleh Inggris untuk menyerang istana. Kala itu kondisi Kraton benar benar dikepung dari berbagai arah oleh sekitar 1000 pasukan Inggris.

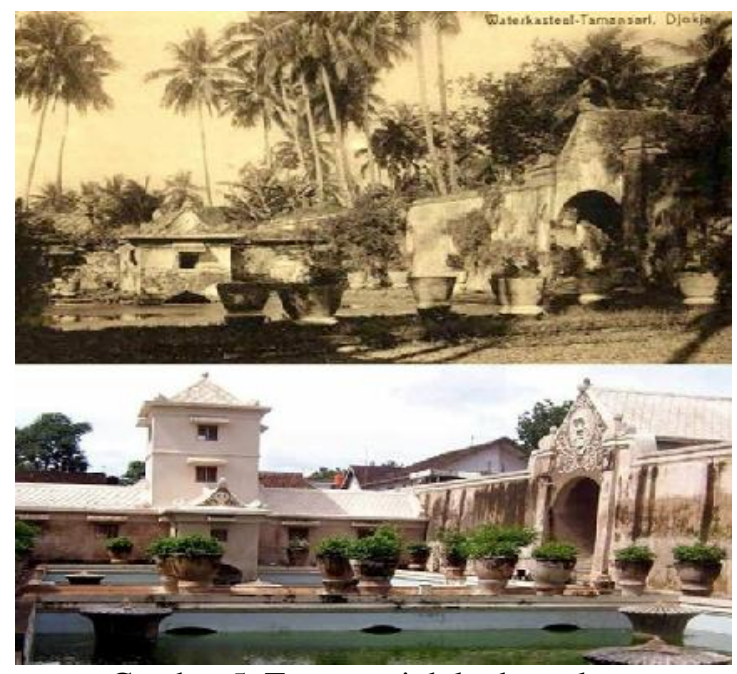

Gambar 5. Tamansari dulu dan sekarang Sumber : Instagram @jogjajamanold, 2019

Sehingga waktu itu, Kraton berhasil dilumpuhkan dan Inggris menjarah barang barang di Kraton. Belum cukup hancur oleh serbuan Inggris, tahun 1867 terjadi gempa besar entah tektonik maupun vulkanik yang 
menghancurkan bangunan Tamansari. Setelah tahun tersebut, kompleks Pesanggrahan Tamansari mulai dipadati oleh perumahan penduduk hingga sekarang. Sehingga kalau ingin melihat bentuk kemegahan Tamansari secara utuh, sangat sulit untuk diwujudkan. Karena harus merelokasi kurang lebih 2.500 rumah penduduk di sekitarnya. Tamansari yang sekarang kita lihat masih di bawah 50\% dari wajah aslinya sendiri ketika masa kejayaannya (kratonjogja, 2018)

\section{Fungsi Bangunan Tamansari}

Fungsi pertama dari Taman Sari yaitu Tempat Pertahanan (Kota Jogjakarta, 200 tahun, 1956:16). Sebagai seorang panglima perang, ahli strategi dan seorang kesatria, Sultan memfasilitasi bangunan Tamansari sebagai tempat pertahanan, fasilitas tersebut antara lain: Benteng yang tinggi dengan baluwer (tempat meriam), Gerbang atau gapuro yang dilengkapi dengan tempat penjagaan para prajurit. Jalan-jalan bawah tanah (urung-urung) dan bangunan tempat kesekretairatan. Dua buah meriam pada kanan kiri gerbang.

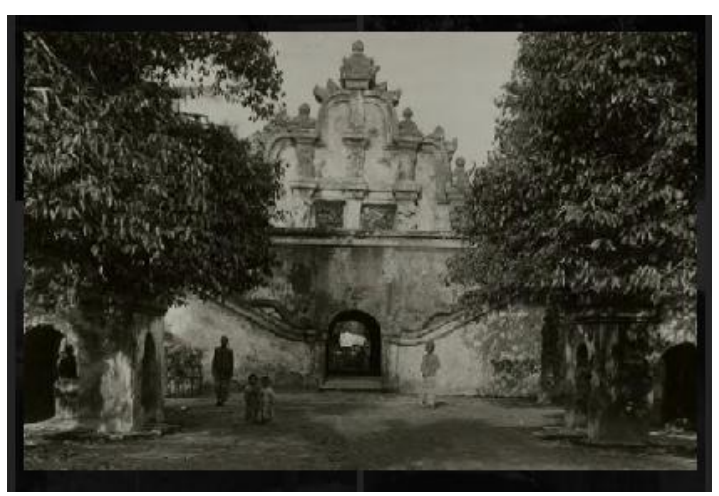

Gambar 6 Tamansari sebagai benteng Sumber : Instagram @jogjajamanold, 2019

Fungsi kedua dari Tamansari yaitu yempat beribadah (Subhekti, 2005:). Santi, pengelola Tamansari mengatakan Tamansari sebagai tempat beribadah juga merupakan tetirah dimana Sultan menenangkan pikiran dan untuk bersemedi. Beberapa Fasilitas untuk aktivitas religius ataupun meditasi, antara lain: Sumur Gumuling, merupakan mesjid bawah air dengan konstruksi dua lantai berbentuk melingkar, di sebelah barat terdapat mihrab dan di lantai bawah untuk sembah yang berjamaah.

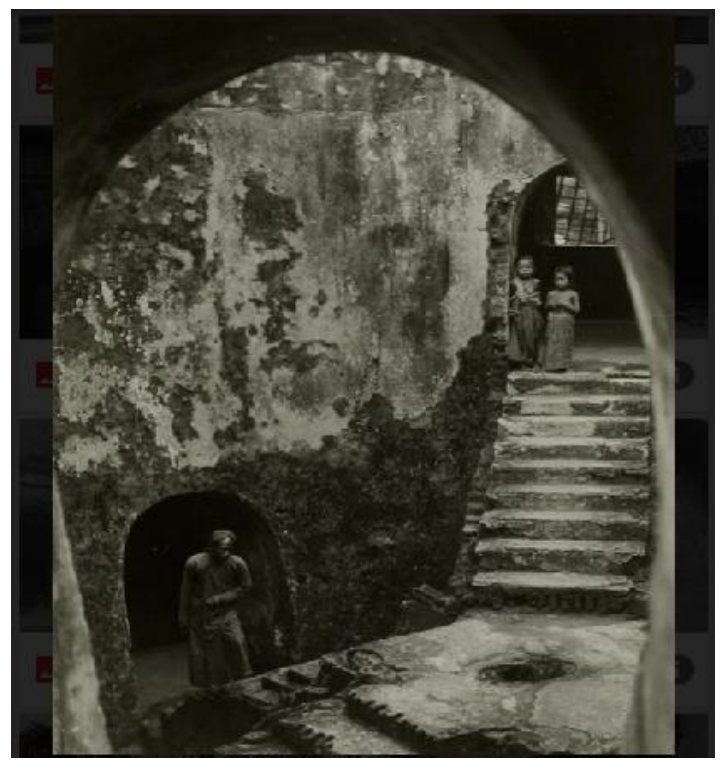

Gambar 7 Sumur Gumuling Tamansari Sumber : Instagram @jogjajamanold, 2019

Fungsi Tamansari yang ketiga merupakan tempat beristirahat dan berekreasi bagi Sultan dan keluarganya (Sukirman, 1988:12). sebagai tempat rekreasi atau peristirahan dapat diketahui dengan adanya beberapa fasilitas pendukungnya, antara lain: umbul, pasiraman, kolam, pertamanan, dan segaran. Dahulu segaran tersebut luasnya sampai dengan segaran Pulo Gedong di sisi timur kraton. Air segaran dialirkan dari sungai Winongo (sebelah barat kota) melalui parit yang sering disebut kali Larangan. 


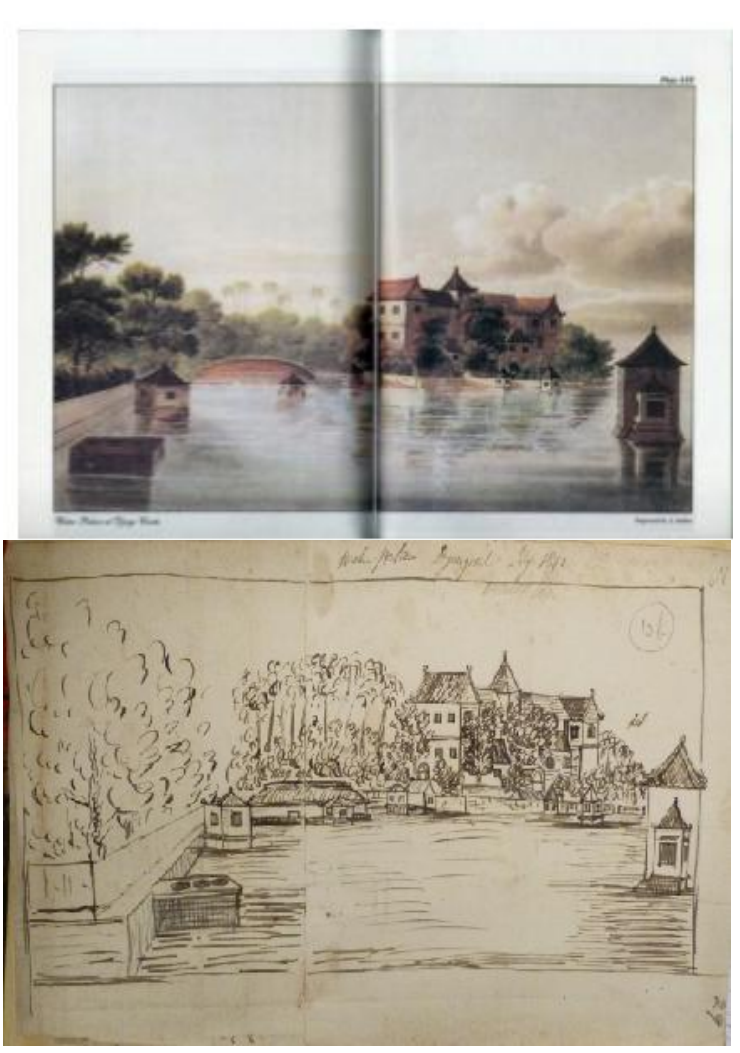

Gambar 8 Visualisasi Tamansari Sumber :Koleksi@jogjajamanold, 2019

\section{Mitos, Pengalaman, dan Imajinasi}

Tamansari merupakan sebuah situs warisan budaya peninggalan kerajaan Mataram yang dibangun pada masa Pemerintahan Sultan Hamengku Buwono I atau Pangeran Mangkubumi. Gaya arsitektur bangunan memiliki nuansa Eropa dan ditambah unsur filosofi Jawa, Budha dan Hindu yang kental. Gaya arsitektur Eropa dilihat dari dinding bangunan yang tebal dan tingginya bangunan. Tebalnya dinding menjadi penanda bahwa fungsi Tamansari sebagai benteng pertahanan Keraton.

Tamansari dibangun pada saat peralihan Mataram dari menganut agama Hindu ke Islam. Hal ini terlihat dari beberapa simbol atau gambar yang terdapat pada bangunan. Setiap simbol tersebut memiliki makna tersendiri. Simbol-simbol ini disebut Sengkalan yang kemudian diwujudkan dalam bentuk rupa, misalnya gambar atau relief disebut sengkalan memet.

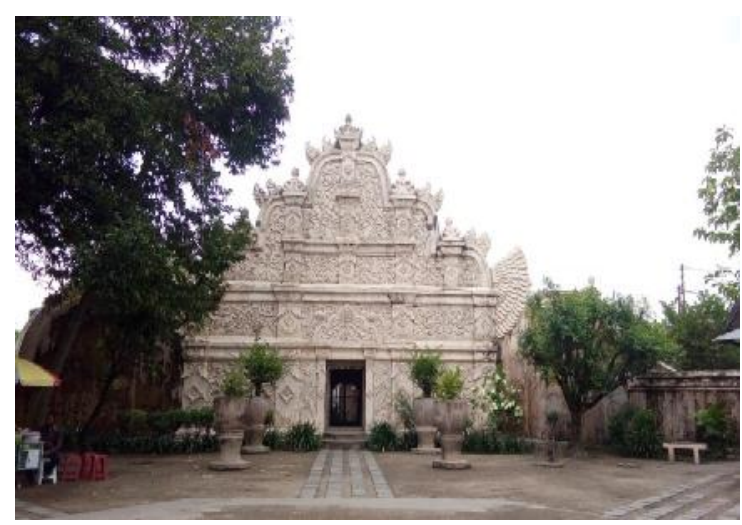

Gambar 9 Relief burung dan tumbuh-tumbuhan Tamansari

Sumber :dokumentasi pribadi, 2019

Selain simbol yang berhubungan dengan Hindu, Tamansari juga melakukan ritual/upacara yang biasa dilakukan saat masih menganut agama Hindu yaitu pemberian sesaji/sesajen. Hal ini dilakukan karena Sutan menganut Islam kejawen. Islam kejawen adalah agama islam yang telah beradaptasi dengan kultur dan tradisi yang kemudian menciptakan sebuah identitas gabungan antara budaya Jawa dan Islam, beberapa menyebut Islam kejawen adalah Islam yang masih mempercayai leluhur atau nenek moyang mereka.

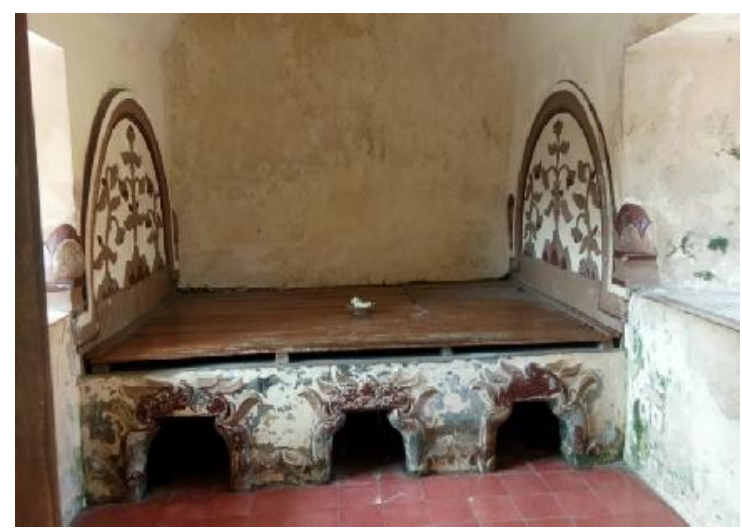

Gambar 10. Sesajen/sesaji

Sumber : Dokumentasi pribadi, 2019

Bentuk dari Islam kejawen yang dianut oleh Sultan dan masih dilakukan sampai saat ini khususnya di Tamansari yaitu pemberian sesajen/sesaji. Pemberian sesajen/sesaji dilakukan untuk menghormati para leluhur, bukan untuk menyembah. Isi sesajen biasanya adalah bunga dan dupa yang dibakar agar memberi aroma wangi. Ketika 
memberi sesaji bacaan yang dibaca pun bacaan ayat-ayat suci seperti Al-fatihah.

Saat ini Tamansari menjadi destinasi wisata yang cenderung ramai dikunjungi wisatawan terutama pada saat akhir pekan. Puing-uing bangunan peninggalan menjadi daya tarik bagi Tamansari yang berarti menjadikan Tamansari berbeda dengan destinasi lainnya. Hal ini disampaikan oleh Pak Ottto (Pemandu wisata) bahwa :

"Tamansari sekarang hanya tinggal bangunan-bangunan sekian persen tapi Tamansari masih menarik banyak wisatawan, disana (Tamansari) bahkan setiap tahun itu selalu meningkat (wisatawan). Tamansari merupakan kawasan keraton menjadi kawasan wisata yang diminati wisatawan dan sekarang disitu ada kampung dan kampung itu adalah bagian dari cerita keberadaan tamansari, itu yang menarik dan ga ad adi tempat lain. Kampung wisata dan kegiatan masyarakatnya. Cerita yang disampaikan komplit yaitu keraton, pantai selatan dan Tamansari."

Berbeda dengan wisata lain yang memiliki satu cerita, Tamansari memiliki tiga cerita yang bisa disajikan kepada wisatawan yaitu Keraton, Tamansari dan Pantai Selatan. Tamansari sebagai wisata budaya bisa memberikan suasana di masa lalu dan rasa nyaman. Hal ini dimungkinkan karena bangunan Tamansari yang jadul seperti bentuk arsitektur, warna bangunan dan merupakan sisa reruntuhan.

Hal ini diungkapkan oleh Rifma (Wisatawan) bahwa :

"Karena Tamansari kan termasuk wisata budaya dan wisata budaya bisa memberikan suasana nyaman dan sedikit membuat kita para wisatawan kembali ke jaman dulu."

\section{Kekuatan Mitos}

Mitos Tamansari adalah suatu cerita yang dipercayai oleh masyarakat setempat sejak nenek moyang mereka terdahulu.
Mitos berkembang dari mulut ke mulut yang diceritakan oleh leluhur dan orang tua mereka dari generasi ke generasi yang tidak memiliki sumber yang jelas. Beredarnya mitos dikalangan masyarakat digunakan oleh pemandu wisata sebagai upaya dalam rangka menarik minat wisatawan berkunjung ke Tamansari.

Mitos tersebut dijadikan bagian dari Tamansari dengan menghubungkan cerita Keraton dan Nyi Roro Kidul dengan Tamansari. Pemandu wisata menyampaikan cerita mitos dengan menunjukkan lokasi mitos kepada wisatawan dan menceritakan kejadian dimasa lalu. Hal ini diutarakan oleh Pak Otto (Pemandu wisata) bahwa :

"Jadi memang di dunia guide mitos itu diceritain, Cuma Tamansari itu mitosnya hanya terkait dengan Ratu pantai selatan, ga jauh dari situ. Tapi apa namanya yah setiap orang beda-beda ceritanya setiap guide semua beda karena itu memang ga ada bukunya ga ada. Itu kan hanya cerita. Awalnya itu cerita, akhirnya kita cerita tentang mitos gito loh. Guide di atas saya itu malah ga,nah kami yang di bawah itu yang menggunakan cerita itu. Kita dulu ngomongnya "opo sih yang menarik wisatawan, yang mitos itu tentang apa sih". Yah karena keraton hubungan dengan pantai selatan yah kita cerita tentang ratu pantai selatan Nyi Roro Kidulnya itu. Tapi itu ga ada bukunya, cuma bikinan kita turuntemurun aja dari cerita orang tua jadi sumbernya itu tidak ada yang bisa dipercay, gada.

Mitos yang beredar selama ini dan dipercayai merupakan cerita orang tua mereka (pemandu wisata). Karena Tamansari memiliki hubungan dengan Keraton dan Nyi Roro Kidul sehingga dibuatlah cerita yang membuat wistawan penasaran dan tertarik untuk berkunjung ke Tamansari. Mitos ini, kini menjadi salah satu atraksi di Tamansari.

Menurut Pak Okto Leando (Pemandu wisata Tamansari) bahwa terdapat 3 mitos Tamansari yang terkenal: 
Pertama, kolam pemandian atau Umbul Binangun yang dulunya digunakan oleh Sultan, para istri/selir, dan putri-putri sultan untuk mandi. Mitos yang beredar mengenai tempat ini yaitu konon Sultan biasa menghabiskan waktu untuk beristirahat di menara/bangunan yang berada di dekat kolam. Menara digunakan Sultan untuk melihat istri atau selir yang sedang mandi. Sultan akan melemparkan bunga dari atas menara untuk memilih diantara permaisuri atau selir yang mandi. Selir/permaisuri yang terkena lemparan bunga diperkenankan mandi di kolam khusus bersama raja yang berada di sebelah selatan bangunan untuk menemani Sultan.

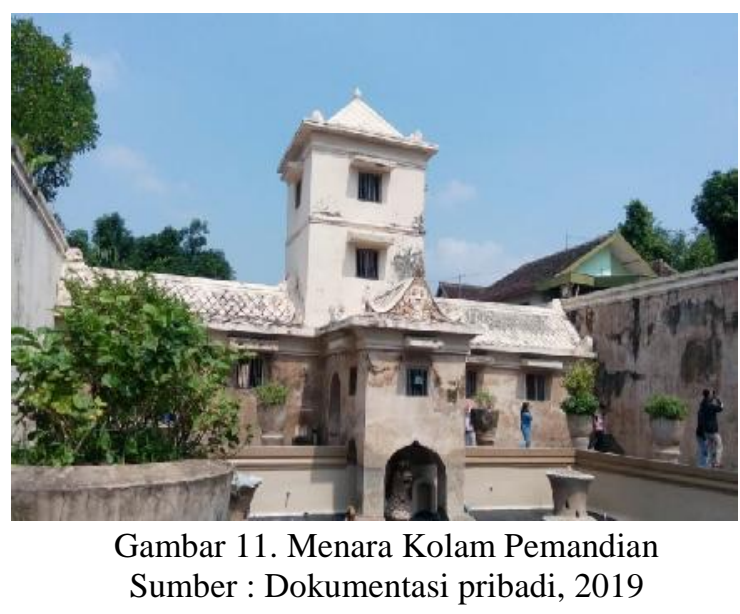

Menurut sejarah kolam pemandian ini dulunya adalah tempat peristirahatan dan rekreasi keluarga Sultan. Permaisuri/selir mapun putri-putri sultan mandi di kolam dalam keadaan menggunakan kemben dan raja berada di menara untuk mengawasi istri dan putri-putrinya yang sedang mandi.

Apabia raja berkenan mandi maka raja akan memanggil atau mengutus salah satu untuk menemai raja mandi. Hal ini diungkapkan oleh Aldo (Anggota Balamuda Taman) bahwa :

"Jadi, mereka tidak TELANJANG. Namun mereka menggunakan kemben (batik sarong). dan Sultan selalu ada di tower Menara di bagian tengah. Konon menara ini digunakan Sultan untuk melihat istri dan selirnya yang sedang mandi. Kolam itu dalamnya hanya 1,5 meter jadi tidak akan tenggelam"
Kedua, Sumur Gumuling terletak di sebelah barat dari Pulo Kenanga. Sumur Gumuling juga dikenal dengan nama masjid bawah tanah karena dulunya bangunan berfungsi sebagai masjid dan terletak di bawah tanah. Sumur gumuling memiliki terdiri dari 2 lantai dan memiliki 1 tangga untuk ke lantai 2. Sumur Gumuling menjadi salah satu spot andalan bagi wisatawan untuk mengabadikan gambar karena bangunan ini memberikan kesan unik.

Mitos mengatakan bahwa lorong bawah tanah bisa tembus sampai ke pantai selatan dan pernah ada wisatawan yang masuk ke lorong tersebut hingga tidak kembali sehingga lorong tersebut ditutup. Pernyataan tersebut disampaikan oleh Pak Otto (Pemandu wisata) bahwa :

"Nah kebenarannya bahkan kita ga tau, kebenarannya lorong itu sampai mana. Cuma kita bisa meyakini mungkin itu salah satu lorong yang tembus ke Keraton karena memang dari Keraton ke Tamansari ada lorong bawah tanah dan itu tidak ditemukan sampai sekarang lorong itu yang mana. Karena itu ada 5 yang masih utuh. Mungkin ini salah satu lorong yang bisa tembus ke Keraton. Lorong itu ditutup agar tidak disalah gunakan dan demi keselamatan wisatawan.Nah cerita ituu berkembang sampai sekarang, bahkan wisatawan pun terutama yang domestik itu selalu menanyakan "Pak lorong yang sampai ke pantai itu, yang mana?" Kami antarkan dan kami ceritakan tapi kami mengatakan itu mitos.”

Selain Lorong Bawah Tanah, Sumur Gumuling juga terdapat mitos yang terkait dengan Nyi Roro Kidul. Mitosnya bahwa, jika Sultan ingin bertemu atau berhubungan dengan Ratu Nyi Roro Kidul, maka Raja akan bersemedi di Sumur Gumuling yang merupakan tempat pertemuan Ratu Pantai Selatan. Padahal fungsi dari bangunan ini adalah sebagai tempat beribadah. Bangunan Sumur Gumuling dibuat bulat melingkar seperti angka satu memiliki makna bahwa tuhan itu satu atau Esa. 
Ketiga, Mitos Pulo Kenanga, konon katanya ketika keluarga Sultan tidak menempati tempat ini sering terdengar suara gamelan dimainkan. Hal ini diyakini bahwa pada saat itu prajurit Nyi Roro kidul berada di Pulo Kenangan untuk memainkan Gamelan. Kebenaran dari mitos ini bahwa Pulo Kenanga adalah sebuah gedung yang berfungsi sebagai tempat peristirahatan dan berberapa kegiatan kesenian seperti seni tari, alat musik dan kerajinan batik.

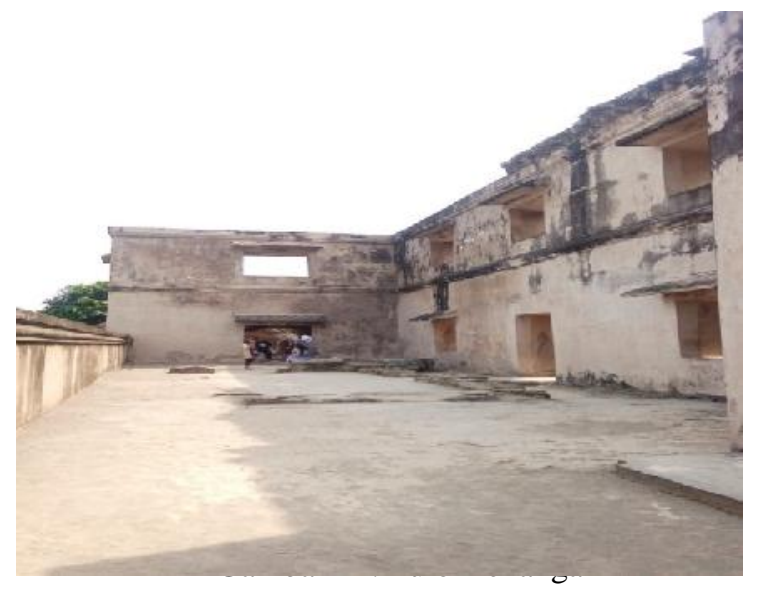

Sumber : Dokumentasi pribadi, 2019

Pulo Kenanga ini pula didirikan sebuah gedung berlantai dua yang dikelilingi tanaman kenanga (Cananga odorata), dinamakan dengan Gedong Kenanga. Posisinya cukup tinggi, membuat orang dapat mengamati kawasan Keraton Yogyakarta dari atasnya. Gedung inilah yang dari kejauhan tampak mengambang di atas air sehingga memunculkan istilah Istana Air (Water Castle). Di sebelah selatan Pulo Kenanga, menyembul bangunan-bangunan kecil yang disebut dengan Tajug. Bangunan kecil ini adalah ventilasi udara untuk terowongan bawah air, jalan masuk menuju Pulo Kenongo tanpa menggunakan sampan.

Secara umum wisatawan menunjukan kesan masih penasaran pada mitos yang ada di Tamansari. Hal ini dimungkinkan karena wisatawan secara umum tidak mengetahui kebenaran cerita dibalik mitos. Meskipun akhirnya mengetahui bahwa mitos tersebut tidak benar beberapa wisatawan masih percaya dengan mitos yang ada di lokasi. Mitos yang berkembang di masyarakat adalah mitos yang dapat dinalar oleh manusia hingga yang tidak masuk akal atau logika.

Alasan mereka percaya pada mitos ini karena menurut mereka mitos yang diceritakan sesuia antara mitos dan tempat kejadian. Hal ini karena mitos berada di lokasi yang masih kental dengan hal yang berhubungan mitos dan sejarah serta kehidupan di masa lalu. Hal ini dapat dilihat dari pernyataan wisatawan bahwa :

"Yang buat aku percaya itu, karena dia nyeritain raja. Raja yang banyak selirnya. Nah di jogja sendiri emang raja itu ada dan emang dulu raja itu emang banyak istri walaupun sekarang cuma satu yah. Nah itu sih yang buat aku percaya sama cerita-cerita di Tamansari meskipun mitos itu boleh dipercaya boleh enggak." (Wisatawan 1)

"Kalau aku sih ini di Jogja dan masih banyak yang seperti itu (mitos) dan sampe sekarang pun masih kental budayanya terus liat-liat ceritanya yang kayak gitu tuh kalau dibayangin tuh masih nyambung dan realistis gitu, yah menurutku itu hampir real cuma kita ga tau aja timingnya pas itu terjadi"(Wisatawan 2)

"jadi, dibilang peryaca ga percaya yah. Kalau aku sih percaya menurut cerita yang beredar bahwa fakta di lapanganya kondisi di lapangannya kayak pemandiannya itu ada, terus ada menara di atas kalau di logika masih nyambung yah kalau aku percaya sih." (Wisatawan 3)

Cerita mitos di lokasi yang masih kental dengan budaya dan tradisi cenderung dipercayai memiliki hubungan dengan sejarah di masa lalu. Adapun alasan utama wisatawan berkunjung ke Tamansari karena mitos. Rasa penasaran terhadap mitos menimbulkan keinginan untuk berkunjung ke Tamansari seperti salah satu pernyataan di bawah ini :

"Kalau aku sih awalnya dari mitos dulu yang diceritain, penasaran dan akhirnya dateng." (wisatawan 4) 
Mitos yang didengar memberikan rasa penasaran sehingga timbul keinginan untuk berkunjung ke lokasi wisata.

\section{Pengalaman Perjalanan}

Pengalaman ini menjadi kenangan yang tak terlupakan bagi wisatawan. Dari hasil wawancara diketahui bahwa pada umumnya wisatawan mengenang pengalaman yang menyenangkan ketika berwisata di Tamansari. Kenangan akan bangunan Tamansaridan kegiatan yang dilakukan senantiasa dikenang bahkan ketika itu sudah terjadi bertahun-tahun. Hal tersebut terlihat dari pernyataan wisatawan berikut :

"Pertama kali ke Tamansari dan sampai sekarang yang diingat bentuk bangunannya yang ga biasa, dan kalau kesini suasananya bagus sambil memandangi bangunan dan sekitar berasa kembali ke masa lalu." (wisatawan 5

"Memori /kenangan yang ada di Tamansari adalah berfoto di spot yang terkenal seperti Sumur Gumuling, Bangunan yang tinggi dan bangunannya unik." (wisatawan 6)

Wisatawan mengenang hal yang dilakukan di Tamansari sebagai tempat untuk kembali ke masa lalu. Jika bangunan pada Tamansari memungkinkan wisatawan memenuhi lamunan dan imajinasi mereka, pemotretan memberi mereka kesempatan untuk mengambil dan membekukan gambar Tamansari sebagai milik mereka sendiri. Mengambil gambar memiliki kepuasan tersendiri yang memiliki hubungan dengan penglamanan berwisata yang bisa dikenang melalui gambar.

Rasa penasaran akan sejarah maupun mitos di lokasi secara tidak langsung akan menambah pengetahuan wisatawan. Pengetahuan akan lokasi diperoleh melalui atraksi penelusuran sejarah dan mitos, wisatawan dapat mengetahui sejarah dan membuktikan mitos yang beredar. Pengalaman Penelusuran sejarah memberikan pengalaman pengetahuan terkait pembangunan Tamansari. Pada wisata
Tamansari, wisatawan mendapatkan pengetahuan tentang sejarah dan mitos yang kemungkinan besar tidak ditemukan secara tertulis di kawasan Tamansari, karena keterangan yang banyak disajikan melalui pemandu wisata.

Keterlibatan maupun pengetahuan yang diperoleh wisatawan ketika di Tamansari memberikan kesan tersendiri yakni rasa kagum terkait arsitektur bangunan Tamansari yang indah dan unik. Hal ini dibuktikan dari penuturan wisatawan :

"Nilai keindahanya itu yah indah karna jaman sekarang. Apalagi yah gaya arsitektur yang kayak gitu tuh dimana lagi bisa ditemuin, terus dibandingin sama bangunanbangunan lain ga sebagus tamansari apalagi yang sumur gumuling ga kepikiran gimana sih orang jaman dulu bisa bentuk bangunannya kayak itu." (wisatawan 7)

\section{Imajinasi Wisatawan}

Imajinasi yang dialami oleh wisatawan yang mengunjungi situs warisan budaya yang terhubung dengan tempat, dapat digambarkan sebagai hal yang menarik. Bagi wisatawan tertentu, pengalaman lokasi wisata hanya sebagian, dan dalam beberapa kasus sama sekali tidak terhubung dengan dunia narasi. Hal ini disampaikan oleh wisatawan sebagai berikut :

"Bangunan yang tinggi berleter " $U$ " kenapa harus menghadap ke selatan nah sebagaimana aku ga tau yah filosofisnya gimana, terus yang kedua itu tempat tidur permaisurinya menhadap ke utara" (wisatawan 1)

"Yah bayangannya pas diceritain aku pikiranya udah kebawa gimana kalau ini masih berlaku sampai sekarang kayak jaman dulu, gimana mereka dan bentukan bangunan aslinya. Aku sih lebih ngebayanginya aku ada disana seperti jaman dulu." (Wisatawan 2)

"Kalau aku sih pas udah dijelasin guidenya liat lokasinya liat tempatnya nah 
itu yah otomatis kebawa ke jaman itu gitu." (wisatawan 3)

Dari para wisatawan ini, mitos hanya sebagian pengalaman yang imajinatif dari lokasi yang mereka kunjungi. Hal ini membawa mereka ke masa lalu, sementara memikiran aspek-aspek lain saat itu. Wisatawan dapat menghubungkan dirinya dengan lokasi dan menjadi bagian dari cerita. Ini memperdalampengalaman imajinasi mereka dengan memasukkan bagian perasaan sebagai bagian dari narasijuga memperkuat memori kunjungan di lokasi wisata :

"Kalau imajinasiku setelah dengar cerita terus liat tempatnya, disitu kan ada tempat yang tinggi bayangan aku disitu Raja berdiri pakai baju raja warna hitam terus eh pakai apa itu yah mahkota raja, nah disitu (kolam) permaisurinya lagi mandi pake kemben dan permaisuri itu agak ngerayungerayu" (Wisatawan 4)

"Kalau aku sih bayanginnya Rajanya di atas terus para permaisurinya di bawah lagi mandi ga pake apa-apa ga pake baju sama sekali, pemandiannya itu mandi bareng semua disitu dan yah ga pake apa-apa. Terus kalau yang sumur gumuling yang bisa tembus ke parangtritis bayanginya wah gimanalah gelapnya di dalam itu terus jalannya sejauh apa karena dari Tamansari ke parangtritis itu lumayan jauh, tapi kalau misalnya ada ilmu gaib gitu kurang paham juga sih.” (Wisatawan 5)

Sementara rasa ketidakpercayaan dan tidak mungkin terhadap lokasi dan mitos yang disampaikan. Wisatawan ini mencoba mencocokkan cerita dan lokasi mitos yang dirasa tidak dapat dilogika :

"Yang saya bayangkan ketika mendengar mitos ini, itu sesuatu yang tidak bisa ditangkap berdasarkan logika manusia Apakah benar lorong itu bisa tembus sampai ke pantai laut selatan sedangkan kalau kita bayangkan dari Taman Sari menuju Pantai Laut Selatan jaraknya sekitar $30 \mathrm{~km}$ sangatlah panjang untuk membangun lorong dari Tamansari menuju Pantai Laut Selatan dan meski kalau misalkan itu tuh bisa menembus ke pantai laut selatan pasti ada suatu portal gaib yang mungkin bisa membuat kita langsung ke pantai laut selatan." (Wisatawan 6)

Berdasarkan pernyataan ke-6 wisatawan, dapat disimpulkan bahwa setiap wisatawan memiliki imajinasi yang beragam. Imajinasi yang dihasilkan wisatawan terkait dengan sejara. Wisatawan hanya bisa membayangkan salah satu atau sebagian dari cerita yang disampaikan dan cerita yang disampaikan pun dapat menghasilkan rasa penasaran dan bahkan penolakan.

Wisatawan membayangkan Tamansari setelah mereka melihat gambar atau visualisasi dari Tamansari. Banyak wisatawan menggambarkan Tamansari seperti sebuah istana megah yang dikelilingi oleh danau dan tanaman yang mendeskripsikan Tamansari adalah tempat yang asri.

"Yah kalau saya membayangkan karena julukannya water castle yaitu Tamansari itu dulu istana yang memang megah dan itu dikelilingi oleh danau buatan yang dialiri dari sungai terlarang yang sekarang udah ga ada dan untuk danaunya itu kalau kita mau lihat yah kampung tamansari itu dulu adalah danau buatan yang mengelilingi tamansari. Jadi Tamansari ini kan Taman itu kan artinya taman dan sari itu artinya asri/indah jadi merupakan taman yang indah. Jadi gambaranya dulu tamansari ini banyak sekali ditumbuhi tanam-tanaman dan dikelilingi oleh danau buatan tadi."(wisatawan 6)

Wisatawan mencoba menghubungkan mitos yang diketahui dengan gambar yang dilihat membayangkan kehidupan seorang Raja yang berkuasa.

"Gambaran yang ada dipikiran aku, Tamansari adalah sebuah tempat yang tidak sembarang orang dapat masuk. Sebuah tempat dimana setiap sudut terdapat tata krama Saat sultan melepas penat dengan melihat permaisuri sedang mandi. Kerajaan 
budaya yang unik dan sejarah yang panjang." (Wisatawan 2)

Membayangkan Tamansari sebagai sebuah Taman yang indah"

"Ada sungai, Taman dipebuhi bungabunga"(Wisatawan 3)

Beberapa wisatawan membayangan Tamansari sebagai "Rekreasi atau istirahat"

"Tempat untukistirahatyang banyaktaman-taman”(Wisatawan 1)

"Ruang khusus buat istirahat yang terdapat sungai dengan bangunan megah" (Wisatawan 4)

"Kerajaan yang bagus di masa lalu yang dikelilingi oleh danau" (Wisatawan 5)

\section{Upaya Membangun Imajinasi Wisatawan Melalui Pengalaman Perjalanan di Wisata Warisan Budaya}

Berdasarkan hasil analisis temuan penulis di lapangan, penulis mencoba membuat upaya membangun imajinasi wisatawan melalui penglaman perjalanan melaluifaktor-faktor yang diadaptasi dari Cheng Fei Lee (2015). Kategori ini didasarkan pada faktor mana yang paling dominanmembangun imajinasi wisatawan di Tamansari.

\section{Fasilitas Penginapan dan Makan}

Fasilitas penginapan dan makan sangat penting untuk menunjang kebutuhan wisata agar wisatawan mendapatkan kemudahan dalam berwisata. Ketersediaan fasilitas menjadi pertimbangan wisatawan dalam melakukan kunjungan. Secara umum wisatawan menunjukan rasa kurang puas terhadap fasilitas yang disediakan. Hal ini dikarenakan fasilitas penginapan belum tersedia untuk wisatawan baik di dalam kawasan maupun disekitar destinasi dengan jarak yang dekat.

Wisatawan merasa penataan warung makan yang ada di Tamansari kurang tertata sehingga mengganggu pemandangan bagi wisatawan.
"Penginapan pasti ada, tapi yah jauh. Kalau yang di dalam itu (warung makan) kebanyakan belum buka terus jajananya sama gitu, misalkan yang depan cilok, yang tengah cilok rata-rata itu jualannya sama jadi kayak kurang variatif aja. Tapi kalau untuk mudahnya nggaknya didapat yah mudah." (Wisatawan 2)

\section{Aksesibilitas Internal}

Wisatawan mengatakan akses di dalam perkampungan membingungkan dengan banyaknya gang-gang dan minimnya papan petunjuk arah seperti pernyataan beriku ini :

"Aksesnya susah kalau udah masuk kampung udah buat bingung soalnya banyak gang-gang” (Wisatawan 3)

"Denah sih ada, petunjuk arah ada tapi minim, soalnya jalannya muter-muter. (Wisatawan 4)

"Menurut aku aksesnya susah kalau udah masuk kampung, yah itu papan petunjuk arahnya kayak ga keliatan aja menurut aku” (Wisatawan 5)

\section{Atraksi Terdekat}

Tamansari memiliki lokasi yang sangat strategis karena berdekatan dengan atraksi lainnya. Beberapa atraksi terdekat dengan Tamansari yang dapat dijangkau wisatawan baik berjalan kaki maupun menggunakan kendaraan. Beberapa atraksi yang berada di sekitar Tamansari seperti Pasar Ngasem, Museum Kraton Yogyakarta, Alun-alun Kidul, Museum Sonobudoyo, Kawasan Malioboro, Titik Nol KM, dan Taman Pintar. Hal ini dapat dilihat dari pernyataan wisatawan berikut ini :

"Tempat wisata sekitar itu bangunannya bangunan tua terus banyak aktivitas budaya di sekitar seperti ngebatik dan orang main musik tradisional kayak di malioboro. (wisatawan 4)

"Suasananya, karena wisata-wisata dekat sinikan bangunan peninggalan yang banyak dan itu gak berubah sampai sekarang" (wisatawan 5) 


\section{Aksesibilitas Eksternal}

Akses eksternal merupakan salah satu bentuk kenyamanan yang dibutuhkan wisatawan. Hal ini terkait mudah sulitnya untuk mencapai lokasi yang dituju baik dari segi transportasi maupun kondisi jalan. Akses yang mudah dan terjangkau membantu wisatawan lebih mudah menuju lokasi wisata. Jalur menuju lokasi sudah dalam kondisi beraspal dan terdapat papan petunjuk arah.

"Akses ke objek lain sangat mudah dan sudah tersedia berbagai transportasi umum." (wisatwan 4)

"Akses transportasi menuju destinasi wisata Tamansari sangat terjangkaubisa menggunakanmobil maupun motor dan Parkirannya pun luas jadi lebih menikmati." (Wisatawan 6)

\section{Sistem Penyediaan Keselamatan dan Darurat}

Penyediaan sistem keamanan dan darurat sangat penting diperhatikan untuk menjaga keamanan wisatawan. Tamansari sendiri penyediaan sistem keamanan keselamatan masih terbilang minim. Mengingat kawasan Tamansari cukup luas dan cenderung ramai dikunjungi wisatawan.

"Yah kalau dilihat emang sistem keamanan maupun keselamatannya masih kurang, tapi kan sejauh ini dan beberapa kali ke Tamansari belum ada kejadian seperti copet atau kriminaltapiada rasa waswas sih kalau lagi rame banget"(wisatawan 4)

"Kalau menurut aku sistem kemanan dan keselamatannya masih kurang banget. Sekalipun belum pernah terjadi hal-hal yang tidak diinginkan, kan keselamatan dan keamanan wisatawan beriwisata harus yang utama." (wisatawan 6)

\section{Atraksi di Tempat}

Wisatawan menujukkan bahwa atraksi yang ada di Tamansari adalah dari segi bangunan yang memiliki gaya arsitektur yang unuk, bentuk ukiran bangunan dan keindahan bangunan. Hal ini didukung dengan pernyataan wisatawan yang menuturkan bahwa.

"Nilai keindahanya itu yah indah karena jaman sekarang apalagi yah gaya arsitektur yang kayak gitu tuh dimana lagi, terus dibandingin sama bangunan-bangunan lain ga sebagus Tamansari apalagi yang sumur gumuling ga kepikiran gimana sih orang jaman dulu bisa bentuk bangunannya kayak itu. (wisatawan 5)

\section{Penyediaan Layanan Informasi}

Penyediaan layanan informasi yang masih terbatas menjadi salah satu kendala dalam memberikan pengetahuan kepada wisatawan. Hal ini dikarenakan pihak Tamansari tidak menyediakan pusat informasisecara khusus, tetapi pusat informasi ini masih berada dalam satu tempat yaitu pada loket pembelian tiket.

"Minim yah, kalau menurut aku kurang jadi ga membantu” (wisatawan 1)

"Wisatawan minim akan info yang didapatkan. Info mengenai Tamansari hanya didapat dari brosur dan guide." (wisatawan 5)

\section{KESIMPULAN}

Mitos menjadi alasan utama wisatawan berkunjung ke Tamansari. Berkembangnya mitos membuat wisatawan percaya. Namun mitos yang beredar adalah cerita yang dibuat oleh pemanduuntuk menarik minat wisatawan untuk berkunjung ke Tamansari. Wisatawan meyakini mitos di Tamansari yang belum pasti kebenaranya.

Mitos yang paling dominan membangun imajinasi wisatawan adalah mitos kolam pemandian karena dirasa masih masuk akal dan memiliki kesesuaian latar tempat dan narasi.

Pengalaman perjalanan wisatawan dipengaruhi oleh mitos, sejarah, dan aktivitas. Wisatawan mendapatkan 
pengalaman melalui keterlibatan dan partisipasinya pada atraksi yang disajikan di lokasi. Pengalaman wisatawan dapat menjadi kenangan melalui pengaruh keterlibatan aktivitas yang terdapat pada Tamansari.

Imajinasi yang didapatkan wisatawan terkait mitos yang ada di lokasi. Wisatawan cenderung membayangkan Tamansari sebagai kejadian di masa lalu dan tempat yang indah.

Faktor yang paling dominan membangun imajinasi wisatawan berdasarkan pengalaman adalah faktor aksesibilitas eksternal, atraksi di tempat, atraksi terdekat.

\section{REFERENSI}

Burns, L., dkk\& Green, B. (2010). Heritage Tourism Handbook: A How-to-Guide for Georgia. Amerika: Georgia

Cahyadi, Rusli. (2009). Pariwisata Pusaka Masa DepanBagi Kita, Alam dan Warisan Budaya Bersama. Jakarta. Unesco \& Program Vokasi Parwisata Universitas Indonesia

Cheng-Fei, Lee. (2015). Tourist satisfaction with factory tour experience.

International Journal of Culture, Tourism and Hospitality Research, 9(3) 261-277. Retrivied https://doi.org/10.1108/IJCTHR-02$\underline{2015-0005}$

Detiknews. ParwisiataWarisanBudaya Makin Diminati Masyarakat Dunia. http://m.detik.com/news/berita/d1511902/pariwisata-warisan-budayamakin-diminati-masyarakat-dunia. (Diakses 23 Febuari 2019)

Dictionary Experience. Retrivied www.dictionary.com (diakses 17 Maret 2019)

Endraswara, Suwardi. (2009). Metodologi Penelitian Folkfore. Yogyakarta: Media Pressindo.
Hardini, Widi. (2018). Memorable Experience Wisatawan pada Restoran Upscale di Bali. Disertasi. Fakultas Pariwisata Universitas Udayana Denpasar. Retrivied https://sinta.unud.ac.id/uploads/dokum en_dir/5f9015f02a44a08974ba57e4523 $\underline{20 \mathrm{e} 77 . \mathrm{pdf}}$

Isnani, Dedi. (2010). Pengertian Cerita Rakyat. Retrivied www.dedisnani.com/2010/05/ceritarakyat-pengertian-cerita-rakyat.html

I Gde Pitana dan I Ketut S. Diarta. (2009). PengantarIlmuPariwisata. Yogyakarta : C.V ANDI

Kangen Jogja?. Reruntuhan Taman Sari, 1915. Instagram, foto by @ jogjajamanold, 17. Retrivied www.instagram.com/p/Buk5w92ltbr/?u $\underline{\text { tm } \text { source }=i g \text { share sheet } \& \text { igshid }=\mathrm{s} 95}$ 3ph9taevy

Kangen Jogja?. Bentukbangunanasli Taman Sari. Instagram, foto by @ jogjajamanold, 17 Maret 2019. Retrivied www.instagram.com/p/BoqSOsUHh13 l?utm_source $=\mathrm{ig}$ _share sheet\&igshid= $\underline{12 \mathrm{bi} 4 \mathrm{nbtd} 1 \mathrm{~g} 4 \mathrm{n}}$

Sejarah Tamansari. Retrivied https://www.kratonjogja.id/tatarakiting-wewangunan/14/bangunanbangunan-tamansari (Diakses, $12 \mathrm{Mei}$ 2019)

Bangunan-bangunan Tamansari. Retrivied https://www.kratonjogja.id/tatarakiting-wewangunan/13/tamansari (Diakses, 12 Mei 2019)

Leite, N. (2014). Afterword: Locating Imaginaries in the Anthropology of Tourism. Retrivied https://core.ac.uk/download/pdf/42548 633.pdf 
Paramita, A \& Lusi K. (2013). Teknik Focus Group Discussion. Buletin Penelitian Sistem Kesehatan, 16(2). 118-124

Pertanika J. Soc. Sci. \& Hum. (2018). The Nature of 'Nature Tourism': Exploring the Role of Images and Imagination in Ecotourism. Retrivied http://www.pertanika.upm.edu.my/

Rafael P.B \& Hadyn, I. (2013). Film and tourism: the imagined place and the place of the imagined.Worldwide Hospitality and Tourism Themes, 5(1),39-54. Retrivied https://doi.org/10.1108/175542113112 $\underline{92439}$

Rijal, C. P., Ghimire, S. (2016). Prospects of Creating Memorable Experience in Nepalese Tourism and Hospitality Industry. Journal of Tourism and Hospitality Education. 6(4). Retrivied https://www.nepjol.info/index.php/JTH E/article/view/14767

Salazar, Noel B. (2010). Towards an Anthropology of Cultural Mobilities Crossings: Journal of Migration and Culture 1(1):53-68. Retrivied https://ssrn.com/abstract=2104217

Schroeder, H. (2009). The role of imagination in experiencing natural environments. In Proceedings of the North Eastern Recreation Research Symposium (pp.13). Retrivied www.nrs.fs.fed.us / pubs/gtr/gtr-nrs-p66papers/02-schroeder-p-66. Pdf

Sheng Chieh-Wen Dan Ming-Chia Chen. (2014), Tourist experience expectattions: questionnaire development and text narrative analysis. International Journal of Culture, Tourism and Hospitality Research, 7,(1) 93 - 104.

Su, Xiaobo. (2010). The Imagination of Place and Tourism Consumption: A Case
Study of Lijiang Ancient Town, China, Tourism Geographies, 12(3), 412 -434.

Sugiyono. (2016). Metode Penelitian Kuantitatif, Kualitatif, dan

$R \& D$.Alfabeta: Bandung.

Undang-Undang Nomor 11 Tahun 2010

Walter,Ute, B. Edvardsson dan Asa Ostrom. (2010). Drivers of Customers Service Experiences: a study in the restaurant industry. Managing Service Quality ,20,(3),236-258. Retrivied http://oru.divaportal.org/smash/get/diva2:403140/FU LLTEXT01

Wantoro, A. (2018). kompasian Beyond Blogging : Pentingnya Berimajinasi. Retrivied http://www.kompasiana.com./aguswant oro/50cd9a413344edc1ce192/pentingn ya-berimajinasi?page $=$ all $($ Diakses 29 Maret 2019)

Yoku Rikona Tito Ismail Majid \& Damayanti. (2016). AnalisisFaktor Tourism Experience Kota Bandung. Jurnal e-Proceeding of Management,3,1025-103. Retrivied file:///C:/Users/user/Downloads/16.04. 870_jurnal_eproc\%20(1).pdf

Subhekti, Y. I. (2005)

PerkembanganTamansariSebagai Kawasan Konservasi dan Pariwisata Kota Yogyakarta. Semarang: Universitas Diponegoro

Sukirman, D. H., (1988). Mengenal Sekilas Bangunan Pasanggrahan Taman Sari Yogyakarta. Yogyakarta: Balai Kajian Sejarah dan Nilai Tradisional. Direktorat Jenderal Kebudayaan. Departemen Pendidikan dan Kebudayaan.

Brosur Tamansari

Akun FP Instagram @ jogjajamanold 